УДК 342

DOI 10.18413/2712-746X-2020-44-3-495-503

\title{
Основы теории безопасности города с точки зрения юридической урбанологии
}

\author{
${ }^{1)}$ Грищенко Л.Л., ${ }^{2)}$ Таболин В.В., ${ }^{3)}$ Корабельникова Ю.Л. \\ ${ }^{1)}$ Академия управления МВД России, \\ Россия, 125171 г. Москва, ул. 3. и А. Космодемьянских, 8 \\ e-mail: VVG_59@mail.ru \\ 2)Государственный университет управления, \\ 109542 г. Москва, Рязанский пр-кт, 99 \\ e-mail: tabolin@mail.ru \\ ORCID: 0000-0002-2418-8189 \\ ${ }^{3)}$ Академия управления МВД России, \\ 125171 г. Москва, ул. 3. и А. Космодемьянских, 8 \\ E-mail: korable79@yandex.ru \\ ORCID: 0000-0002-2461-9049
}

\begin{abstract}
Аннотация. Российская Федерация является высоко урбанизированной страной. Представители истории, социологии, экономики и других наук давно ведут исследования различных аспектов городской жизнедеятельности. Юридическая теоретическая наука существенно отстает в этом вопросе, в частности, остается мало изученным правовое формирование системы безопасности человека в городе. В связи с этим авторами с позиции юридической урбанологии дан обзор научных трудов представителей различных наук о городе, выделены объекты и методы исследования, которые носят системный, структурно-функциональный и специальный характер. Представлено авторское понятие города и его безопасности, приведены классификации угроз для его жителей, предложена методика их оценки на основе концепции приемлемого риска, представлено законодательство об обеспечении безопасности в городе и специальный паспорт безопасности города. Выделены негативные последствия и характер их влияния на состояние жизнедеятельности города. Результаты исследования могут иметь практическое применение при решении проблем безопасности города как части общенациональной задачи по обеспечению безопасности и благополучия человека.
\end{abstract}

Ключевые слова: право, чрезвычайная ситуация, угрозы, риски, негативные последствия, методы анализа, органы и силы обеспечения.

Благодарности: исследование выполнено в рамках гранта РФФИ № 19-011-00720 «Разработка научных основ юридической урбанологии как нового комплексного направления в юридической науке о городах».

Для цитирования: Грищенко Л.Л., Таболин В.В., Корабельникова Ю.Л. 2020. Основы теории безопасности города с точки зрения юридической урбанологии. NOMOTHETIKA: Философия. Социология. Право. 45 (3): 495-503. DOI 10.18413/2712-746X-2020-44-3-495-503 


\title{
Fundamentals of the theory of city security from the point of view of legal urbanology
}

\author{
${ }^{1)}$ Leonid L. Grischenko, ${ }^{2)}$ Vladimir V. Tabolin, ${ }^{3)}$ Yulia L. Korabelnikova \\ ${ }^{1)}$ Academy of management of the Ministry of internal Affairs of Russia, \\ 8 Z. and A. Kosmodemyanskikh St, Moscow, 125171, Russia \\ e-mail: VVG_59@mail.ru \\ ${ }^{2)}$ State university of management, \\ 99 Rjazanskij pr-kt, Moscow, 109542, Russia \\ e-mail: tabolin@mail.ru \\ ORCID: 0000-0002-2418-8189 \\ ${ }^{3)}$ Academy of management of the Ministry of internal Affairs of Russia, \\ 8 Z. and A. Kosmodemyanskikh str., Moscow, 125171, Russia \\ E-mail: korable79@yandex.ru \\ ORCID: 0000-0002-2461-9049
}

\begin{abstract}
The Russian Federation is a highly urbanized country. Representatives of history, sociology, economics, and other sciences have been conducting research on various aspects of urban life for a long time. Legal theoretical science significantly lags in this issue the legal formation of the human security system in the city remains poorly studied. In this regard, from the standpoint of legal urbanology, the authors reviewed the scientific works of representatives of various sciences about the city, identified objects and research methods that are systemic, structural-functional, and special in nature. The author's concept of the city and its safety is presented, classifications of threats to its residents are presented, a methodology for their assessment based on the concept of acceptable risk is proposed, legislation on ensuring safety in the city and a special safety passport of the city are presented. Highlighted the negative consequences and the nature of their impact on the state of the city's life. The results of the study can have practical application in solving city safety problems as part of the national task of ensuring human safety and well-being.
\end{abstract}

Keywords: law, emergency situation, threats, risks, negative consequences, methods of analysis, bodies and forces of support

Acknowledgements: the study was carried out within the framework of the RFBR grant No. 19-01100720 "Development of scientific foundations of legal urbanology as a new complex direction in the legal science of cities".

For citation: Grischenko L.L., Tabolin V.V., Korabelnikova Y.L. 2020. Fundamentals of the theory of city security from the point of view of legal urbanology. NOMOTHETIKA: Philosophy. Sociology. Law series. 45 (3): 495-503 (in Russian). DOI 10.18413/2712-746X-2020-44-3-495-503

\section{Введение}

Российская Федерация при всей своей огромной территории и достаточно невысокой средней плотности населения (около 2 человек на квадратный километр) является высоко урбанизированной страной, в которой почти три четверти населения проживает в городах, что говорит об актуальности научных исследований городов для целого комплекса общественных наук [Меньшикова, 2016]. Одни науки, такие как история [Рожков, 1920; Фроянов, Дворниченко, 1988], социология [Зиммель и др., 1905], экономика [Велихов, 1996], урбанистика [Jacobs, 1961] и география [Семенов-Тян-Шанский, 1910] уже достаточно давно ведут исследования различных аспектов городской жизнедеятельности, и в рамках этих дисциплин сложились свои теории города. Философия [Горнова, 2015], психология [Дробышева, Журавлев, 2016], политология [Balbim, 2016], экология [Устюгова, 
2013] и юриспруденция [Таболин, 2019] только в последние десятилетия стали развивать это научное направление.

По нашему мнению, юридическая теоретическая наука существенно отстает в этом вопросе, т.к. «увлекшись» классической теорией государства и права ученые-правоведы не обратили внимание на новые тенденции в формировании «городских государств» и новой научной концепции «замены» государств на систему глобальных городов [Терборн, 2013], которые в свою очередь уже сейчас создают целый ряд серьезных правовых проблем в обеспечении достойного и безопасного уровня жизни для населения.

Юридическая урбанология представляет собой новое направление в юридической науке, объединяющее с позиции права знания различных отраслей гуманитарной и естественной науки о закономерностях возникновения, развития и функционирования городской цивилизации вообще и города в частности, отрасли и институты права, регулирующие общественные отношения, возникающие в социальных, экономических, политических, градостроительных, жилищно-коммунальных и других процессах жизнедеятельности городского населения, о правовом формировании системы безопасности человека в городе, стимулировании позитивных тенденций в процессах урбанизации, способствующих устойчивому развитию государства и общества.

Необходимо подчеркнуть важность такого комплексного подхода в исследовании проблем безопасности города как части общенациональной задачи по обеспечению безопасности и благополучия человека [Кузнецов, 2005]. Рассмотрим некоторые теоретические аспекты обеспечения безопасности города.

\section{Объекты и методы исследования}

Главным объектом изучения данной темы, конечно же, является город, во всем многообразии различных подходов к содержанию этого понятия в общественных науках [Загоруйко, Главацкий, 2010]. С позиции юридической урбанологии город можно определить как комплекс сложных междисциплинарных общественных отношений, урегулированных социальными, правовыми и обычными нормами, обеспечивающими необходимый уровень и качество жизни и безопасности человека в социальной, экономической, политической, психологической, урбанистической, коммунальной и других сферах городского пространства.

Определяя основу безопасности человека в городе необходимо отметить, что она представляет из себя сложную систему, состоящую из различного рода дифференцированных показателей по минимизации угроз глобального, общего и персонального плана, имеющую прямо пропорциональную зависимость от месторасположения, структуры, предназначения и состояния систем его жизнеобеспечения.

Исходя из сложности и разноплановости объектов исследования, применяются системный и структурно-функциональный методы, исторический, логический и статистический методы. Из специальных методов использованы формально-юридический и сравнительно-правовой методы, метод правового моделирования и толкование права.

\section{Безопасность города}

Под безопасностью города следует понимать реальные объективные условия, в которых находится данный город, когда действие внешних и внутренних факторов не приводит к негативным процессам, которые могут создать неблагоприятные или опасные условия существования для горожан, в соответствии с установленными нормами и правилами их поведения, факторами угроз их здоровью и жизни в городе.

Находясь в городской среде, человек постоянно подвергается как объективным, так и субъективным опасностям, среди которых следует выделить, во-первых, глобальные угрозы: извержение вулканов; эпидемии; космические воздействия; кардинальные клима- 
тические изменения; искусственный интеллект и иные, пока еще не известные угрозы. Вовторых, общие объективные угрозы: военные, техногенные, природные, коммуникативные, информационные. В-третьих, угрозы социально-политического свойства: попытки насильственного изменения конституционного строя Российской Федерации; захват или присвоение власти; вооруженный мятеж; массовые беспорядки; террористические акты; блокирование или захват особо важных объектов или отдельных местностей; подготовка и деятельность незаконных вооруженных формирований; межнациональные, межконфессиональные и региональные конфликты, сопровождающиеся насильственными действиями, создающие непосредственную угрозу жизни и безопасности граждан, нормальной деятельности органов государственной власти и органов местного самоуправления, преступность, насильственное разрушение сложившегося и навязывание чуждого мировоззрения, нравственное развращение и физическое растление, несанкционированное (непреднамеренное) энергоинформационное воздействие на мозг человека и т.д. Лавинообразно актуализируются риски в сфере личного достоинства, правозащиты [Butko et al., 2017].

При наложении перечисленных угроз на систему безопасности конкретного города они приобретают ряд существенных свойств:

1. Глобальные и общие опасности (угрозы) характерны для всех городов мира, но и они имеют дифференцированный характер своего воздействия (наводнения угрожают приморским городам и городам, расположенным вдоль рек; разрушительные землетрясения могут произойти в сейсмически опасных районах; эпидемии в большей мере затрагивают крупные города и т.п.).

2. В крупных городах (мегаполисах) значительная концентрация людских потоков и их векторная направленность в зависимости от времени дня, недели, года и их интересов (часы пик, дачный сезон, массовые общественно-политические, спортивные, культурные и религиозные мероприятия и т.д.) сами по себе при определенных негативных условиях становятся поводом для чрезвычайных обстоятельств.

3. Высокая потребительская зависимость жителей города от внешних источников воды, энергии, продовольствия и лекарств создает их уязвимость при угрозе дефицита или отсутствия необходимых средств жизнеобеспечения.

4. Постоянное накопление отходов жизнедеятельности человека приводит к перманентным экологическим угрозам при их утилизации на территориях, прилегающих к городу.

5. Лавинообразная опасность распространения инфекционных заболеваний.

6. Подверженность определенной части городского социума паническим настроениям при возникновении явных или спровоцированных вымышленных угроз приводит к серьезным психологическим травмам и неадекватным действиям.

7. Значительное влияние на человека в городе электромагнитного излучения от большого количества приемо-передающих и усилительных устройств, бытовой техники и коммуникационных устройств.

8. Снижение межличностных коммуникаций между жителями города при высокой плотности населения и уровне миграции дает возможность для распространения криминального элемента и его безнаказанной преступной деятельности и т.д.

При всей сложности проблем обеспечения безопасности городского социума в условиях неуклонного возрастания интенсивности появления и реализации угроз сегодня жизненно необходима адекватная стратегия противодействия. Однако для создания такой стратегии необходим подбор компонентов, опираясь на которые можно будет создавать целостную систему обеспечения безопасности человека в городе в условиях урбанизации. Составляющими таковой системы могут стать правовая основа обеспечения безопасности человека в городе, методика измерения уровня угроз городскому социуму; паспорт безопасности города; органы обеспечения безопасности города и их функции.

Правовая основа обеспечения безопасности человека в городе - это развивающаяся и регулируемая, определённым образом упорядоченная совокупность правовых норм, активизация которых происходит при угрозе или возникновении опасных условий жизнедеятельно- 
сти человека и устранение которых требует проведения экстренных мер со стороны органов государственного и муниципального управления города. Универсальный инструмент реализации правовых установлений - юридическая ответственность [Makogon et al., 2017].

Основными нормативными источниками, регламентирующими данную деятельность, являются следующие:

- Конституция РФ, федеральные конституционные законы от 30.05.2001 № 3-ФКЗ «О чрезвычайном положении» и от 30.01.2002 № 1-ФКЗ «О военном положении»;

- федеральные законы от 21.12.1994 № 68-Ф3 «О защите населения и территорий от чрезвычайных ситуаций природного и техногенного характера», от 12.02.1998 № 28-Ф3 «О гражданской обороне», от 22.07.2008 № 123-Ф3 «Технический регламент о требованиях пожарной безопасности», от 21.07.1997 № 117-Ф3 «О безопасности гидротехнических сооружений», от 16.01.2018 № 151-Ф3 «Об аварийно-спасательных службах и статусе спасателей» и др.;

- указы Президента РФ от 11.07.2004 № 991 «О совершенствовании единой государственной системы предупреждения и ликвидации чрезвычайных ситуаций», от 13.11.2012 № 1522 «О создании комплексной системы оповещения населения об угрозе возникновения или о возникновении чрезвычайной ситуации»;

- постановления Правительства РФ от 04.09.2003 № 547 «О подготовке населения в области защиты от чрезвычайных ситуаций природного и техногенного характера», от 03.11.2006 № 794 «О единой государственной системе предупреждения и ликвидации чрезвычайных ситуаций» и др.;

- нормативные правовые акты субъектов России. Например, 05.11.1997 в г. Москве был принят закон № 46 «О защите населения и территорий города от чрезвычайных ситуаций природного и техногенного характера», а в 2010 году распоряжением Правительства Москвы от 16 апреля № 707-РП утверждена Концепция комплексной безопасности города Москвы;

- муниципальные правовые акты, регулирующие отношения, возникающие в связи с защитой населения и территорий муниципальных образований от чрезвычайных ситуаций.

Необходимо отметить, и это апробировано на практике, абсолютная безопасность для человека, где бы он ни находился, невозможна по факту. Можно говорить о снижении уровня опасности, что и явилось основой для создаваемой с конца 70-х годов прошлого столетия концепции приемлемого (допустимого) риска (Вирт). Суть этого подхода заключается в снижении опасности до такого низкого уровня, который приемлет общество в данный период времени [Актуальные тенденции развития..., 2018]. По данной теории нулевая вероятность наступления того или иного негативного события не может быть применена в качестве истины.

К настоящему моменту сложились представления о величинах приемлемого (допустимого) и неприемлемого риска. Приемлемым риском называется такой уровень опасности, смертности, травматизма или инвалидности людей, с которым на данном этапе развития общество может смириться ${ }^{1}$. В настоящее время по международной шкале принято считать, что действие угроз должно находиться в пределах от $10^{-6}$ до $10^{-7}$ вероятности возникновения (10-6 является максимально приемлемым уровнем индивидуального риска). В национальных российских правилах эта величина используется для оценки, например, пожарной и радиационной безопасности.

Анализ риска обычно включает оценку диапазона возможных негативных последствий тех или иных событий, ситуаций или обстоятельств и соответствующих им вероятностей для определения уровня риска, обоснованную транспозицию теории и практики

1 Энциклопедия безопасности жизнедеятельности. Концепция приемлемого риска. URL: http://bzhde.ru/tag/priemlemyj-risk (дата обращения: 15 июля 2020). 
[Новикова, Анисимов, 2008]. Однако в некоторых случаях, например, когда вероятность события чрезвычайно низка или последствия незначительны, для принятия решений может быть достаточно исследований только общих параметров.

Методы, используемые при анализе риска, могут быть качественными, количественными или смешанными. Степень глубины и детализации анализа зависит от конкретной ситуации, доступности достоверных данных и потребностей города. Как правило, методы и степень детализации анализа должны быть установлены в соответствии с правовыми и обязательными требованиями, предусмотренными в федеральном и региональном законодательстве.

При этом для гармонизации в юридическом процессе [Макогон, 2017] считаем целесообразным на основе нормативно-правовых установлений федерального, регионального и муниципального уровней разработку так называемого паспорта безопасности для каждого конкретного города. Целью разработки паспорта безопасности является проведение всестороннего анализа опасностей, определение показателей степени риска для населения, разработка мероприятий по снижению риска и смягчению последствий угроз, а также предупреждению распространения негативных последствий. Паспорт безопасности города может стать инструментом при прогнозировании политического, экономического и социального развития города, что является важнейшим условием предупреждения негативных тенденций в различных областях жизни и функционирования в сложных условиях.

Структурно паспорт безопасности города может включать общие сведения о городе (планировка, транспорт, социально-экономические показатели, преступность, система органов власти и управления), сведения о численности населения и его демографические и миграционные характеристики, уровень жизни и др., сведения об угрозах и прогноз последствий возникновения чрезвычайных ситуаций (ЧС) и чрезвычайных обстоятельств (ЧО), оценку социально-экономических последствий различного рода угроз, перечень сил и средств, привлекаемых для обеспечения предупреждения и ликвидации ЧС и ЧО, перечень мер по всестороннему обеспечению предупреждения, пресечения и ликвидации ЧС и ЧО, определение специального органа управления на период ликвидации последствий ЧС и ЧО и др.

В настоящее время к органам и силам обеспечения безопасности города, которые в зависимости от сложности и опасности ЧС и ЧО могут привлекаться к их ликвидации, следует отнести следующие:

- формирования поисково-спасательной службы МЧС России;

- военизированные и невоенизированные противопожарные, поисковые, аварийно-спасательные, аварийно-технические формирования федеральных органов исполнительной власти;

- силы Государственной противопожарной службы МЧС России;

- формирования и учреждения Всероссийской службы медицины катастроф;

- формирования ветеринарной службы и службы защиты растений Министерства сельского хозяйства и продовольствия Российской Федерации;

- военизированные службы по активному воздействию на гидрометеорологические процессы Федеральной службы России по гидрометеорологии и мониторингу окружающей среды; уровней;

- формирования гражданской обороны территориального, местного и объектного

- специально подготовленные силы и средства войск гражданской обороны, других войск и воинских формирований, предназначенных для ликвидации чрезвычайных ситуаций; энергии;

- аварийно-технические центры Министерства Российской Федерации по атомной 
- службы поискового и аварийно-спасательного обеспечения полетов гражданской авиации Федеральной авиационной службы России;

- аварийно-спасательные службы и формирования Федеральной службы морского флота России, Федеральной службы речного флота России;

- нештатные аварийно-спасательные формирования города;

- общественные аварийно-спасательные формирования;

- части радиационной, химической и биологической защиты и инженерных войск Минобороны России;

- территориальные органы МВД России; Федерации;

- подразделения Федеральной службы войск национальной гвардии Российской

- подразделения органов уголовно-исполнительной системы;

- федеральные органы безопасности;

- в исключительных случаях на основании указа Президента РФ могут привлекаться Вооруженные Силы РФ, другие войска, воинские формирования и органы.

Привлечение федеральных силовых и правоохранительных органов может осуществляться только в строгом соответствии с федеральным законодательством и положениями о данных органах. При этом органы государственного и муниципального управления могут осуществлять согласование действий сил и средств вышеназванных структур по конкретным задачам, времени и месту. Кроме того, в случае угрозы или возникновении ЧС и ЧО межрегионального масштаба могут привлекаться федеральные резервы и структуры смежных территорий. Все это должно отражаться в паспорте безопасности города и согласовываться на межрегиональном и федеральном уровнях.

\section{Заключение}

Несомненно, система безопасности российских городов должна быть неотъемлемой частью системы национальной безопасности страны, поскольку большинство современных угроз носят глобальный или национально-территориальный характер. Однако городские власти и органы управления должны быть подготовлены к действиям в условиях различных негативных факторов, воздействующих на население. Как показала практика борьбы с вирусом COVID-19, этот аспект играет большую роль в обеспечении безопасности жителей. Неквалифицированные действия, растерянность, испуг должностных лиц города приводит к осложнению чрезвычайной ситуации и ее негативных последствий. Практическая отработка различных вариантов чрезвычайных ситуаций и обучение населения действиям в таких ситуациях позволят избежать серьезных негативных последствий.

По нашему мнению, Россия обладает достаточно развитым законодательством и подзаконными актами, необходимыми силами и средствами по эффективному предупреждению и ликвидации чрезвычайных ситуаций в городах.

\section{Список литературы}

1. Актуальные тенденции развития и совершенствования местного самоуправления на современном этапе «Город - территория безопасности». Отв. ред. С.В. Розенко. Ханты-Мансийск, 292 с.

2. Бюхер К., Майр Г., Зиммель Г., Вентиг Г., Петерман Т., Шефер Д. 1905. Большие города, их общественное, политическое и экономическое значение. СПб., Просвещение, 204 с.

3. Вагин В.В. Социология города. URL: www.gumer.info/bibliotek_Buks /Sociolog/Vagin/07.php (дата обращения: 16 июля 2020).

4. Велихов Л.А. 1996. Основы городского хозяйства: Общее учение о городе, его управлении, финансах и методах хозяйства. В 2-х частях. М., Наука, 400 с.

5. Горнова Г.В. 2015. Философия города. М., ФОРУМ: ИНФРА-М, 344 с.

6. Дробышева Т.В., Журавлев А.Л. 2016. Город как объект исследования в социальной психологии: к истории вопроса. Институт психологии РАН. 1: 196-213. 
7. Загоруйко И.Ю., Главацкий В.Б. 2010. Определение понятия «город» как концептуальная основа разработки механизмов устойчивого развития моногородов. Стратегия развития экономики. 5 (72): 29-32.

8. Кузнецов В.Н. 2005. Общенациональная цель: безопасность и благополучие человека как фундаментальная проблема российских общественных наук. Общество и право. 1 (7): 14-54.

9. Макогон Б.В. 2017. Методологически опорная трактовка юридического процесса. Наука и образование: хозяйство и экономика; предпринимательство; право и управление. 1 (80): 32-35.

10. Меньшикова Е.П. 2016. Науки, обслуживающие сложнейшую модель общества - город. Известия ВУЗов. Строительство. 8: 85-91.

11. Новикова А.Е., Анисимов А.П. 2008. Экологические правозащитные риски: проблемы теории и практики. Адвокатская практика. 4: 5-7.

12. Рожков Н.А. 1920. Город и деревня в русской истории. Краткий очерк экономической истории России. М., Гос. изд-во, 103 с.

13. Семенов-Тян-Шанский В.П. 1910. Город и деревня в европейской России: очерк экономической географии. СПб, Тип. В.Ф. Киршбвума, 212 с.

14. Таболин В.В. 2019. Правовая теория современного российского города. М., Юрайт, 358 с.

15. Терборн Й. 2013. Как понять города: современный кризис и идея городов без государства. Журнал социологии и социальной антропологии. 1: 20-40.

16. Устюгова Е.Н. 2013. От экологии города к экологии человека. Вестник Ленинградского государственного университета им. А.С. Пушкина: 97-107.

17. Фроянов И.Я., Дворниченко А. Ю. 1988. Города-государства Древней Руси. Л., 198 с.

18. Butko, L.V., Markhgeym, M.V., Novikova, A.E., Pozharova, L.A., Tonkov, E.E. 2017. Personal Dignity in the European Legal Culture. Journal of History Culture and Art Research, 6 (4): 296-303 p.

19. Jacobs J. 1961. The death and life of great American cities. New York, Vintage Books, $468 \mathrm{c.}$

20. Makogon B.V., Savel'eva I.V., Lyahkova A.I., Parshina A.A., Emel'anov A.S. 2017. Interpretation of legal responsibility as a universal instrument of procedural legal restrictions. The Turkish Online Journal of Design Art and Communication, 7 (S-APRLSPCL): 328-332.

21. The geopolitics of cities: old challenges, new issues 2016. editor R. Balbim. Brasilia, Institute for Applied Economic Research, 360 p.

\section{References}

1. Aktual'nye tendencii razvitija i sovershenstvovanija mestnogo samoupravlenija na sovremennom jetape «Gorod - territorija bezopasnosti». [Current trends in the development and improvement of local self-government at the present stage of the "City-territory of security"]. 2018. Ed. S.V. Rozenko. Hanty-Mansijsk, 292 p.

2. Bjuher K., Majr G., Zimmel' G., Ventig G., Peterman T., Shefer D. 1905. Bol'shie goroda, ih obshhestvennoe, politicheskoe i jekonomicheskoe znachenie. [Big cities, their social, political and economic significance]. S.-Pb., Publ. Prosveshhenie, 204 p.

3. Vagin V.V. Sociologija goroda. [Sociology of the city]. URL: www.gumer.info/bibliotek_Buks/Sociolog/Va-gin/07.php (data obrashhenija: 16 ijulja 2020).

4. Velihov L.A. 1996. Osnovy gorodskogo hozjajstva. Obshhee uchenie o gorode, ego upravlenii, finansah i metodah hozjajstva. [Fundamentals of urban economy: General teaching about the city, its management, Finance and methods of economy]. In 2 parts. M., Publ. Nauka, 400 p.

5. Gornova G.V. 2015. Filosofija goroda. [The philosophy of the city]. M., Publ. FORUM: INFRA-M, $344 \mathrm{p}$.

6. Drobysheva T.V., Zhuravlev A.L. 2016. Gorod kak ob\#ekt issledovanija v social'noj psihologii: $\mathrm{k}$ istorii voprosa. [The city as an object of research in social psychology: a history of the issue]. Institut psihologii RAN. 1: 196-213.

7. Zagorujko I.Ju., Glavackij V.B. 2010. Opredelenie ponjatija «gorod» kak konceptual'naja osnova razrabotki mehanizmov ustojchivogo razvitija monogorodov. [Definition of the concept of "city" as a conceptual basis for developing mechanisms for sustainable development of single-industry towns]. Strategija razvitija jekonomiki. 5 (72): 29-32.

8. Kuznecov V.N. 2005. Obshhenacional'naja cel': bezopasnost' i blagopoluchie cheloveka kak fundamental'naja problema rossijskih obshhestvennyh nauk. [National goal: human security and wellbeing as a fundamental problem of Russian social Sciences]. Obshhestvo i pravo. 1 (7): 14-54. 
9. Makogon B.V. 2017. Metodologicheski opornaja traktovka juridicheskogo processa. [Methodological reference interpretation of the legal process]. Nauka i obrazovanie: hozjajstvo i jekonomika; predprinimatel'stvo; pravo i upravlenie. 1(80): 32-35.

10. Men'shikova E.P. 2016. Nauki, obsluzhivajushhie slozhnejshuju model' obshhestva - gorod. [The Sciences that serve the most complex model of society-the city]. Izvestija VUZov. Stroitel'stvo. 8: 85-91.

11. Novikova A.E., Anisimov A.P. 2008. Jekologicheskie pravozashhitnye riski: problemy teorii i praktiki. [Environmental human rights risks: problems of theory and practice]. Advokatskaja praktika. 4: 5-7.

12. Rozhkov N.A. 1920. Gorod i derevnja v russkoj istorii. Kratkij ocherk jekonomicheskoj istorii Rossii. [City and village in Russian history. A brief outline of the economic history of Russia]. M., Publ. Gos. izd-vo, 103 p.

13. Semenov-Tjan-Shanskij V.P. 1910. Gorod i derevnja v evropejskoj Rossii: ocherk jekonomicheskoj geografii. [Cities and villages in European Russia: an essay on economic geography]. SPb., Publ. V.F. Kirshbvuma, 212 p.

14. Tabolin V.V. 2019. Pravovaja teorija sovremennogo rossijskogo goroda. [Legal theory of the modern Russian city]. M., Publ. Jurajt, 358 p.

15. Terborn J. 2013. Kak ponjat' goroda: sovremennyj krizis i ideja gorodov bez gosu-darstva. [How to understand cities: the modern crisis and the idea of cities without a state]. Zhurnal sociologii i social'noj antropologii. 1: 20-40.

16. Ustjugova E.N. 2013. Ot jekologii goroda $\mathrm{k}$ jekologii cheloveka. [From city ecology to human ecology]. Vestnik Leningrad-skogo gosudarstvennogo universiteta im. A.S. Pushkina: 97-107.

17. Frojanov I.Ja., Dvornichenko A. Ju. 1988. Goroda-gosudarstva Drevnej Rusi. [City-States of Ancient Russia]. L., 198 p.

18. Butko, L.V., Markhgeym, M.V., Novikova, A.E., Pozharova, L.A., Tonkov, E.E. 2017. Personal Dignity in the European Legal Culture. Journal of History Culture and Art Research. T. 6. 4: 296-303.

19. Jacobs J. 1961. The death and life of great American cities. New York, Vintage Books, 468.

20.Makogon B.V., Savel'eva I.V., Lyahkova A.I., Parshina A.A., Emel'anov A.S. Interpretation of legal responsibility as a universal instrument of procedural legal restrictions. The Turkish Online Journal of Design Art and Communication. 2017. T. 7. № S-APRLSPCL: 328-332.

21. The geopolitics of cities: old challenges, new issues 2016. editor R. Balbim. Brasilia, Institute for Applied Economic Research, 360 p.

\section{ИНФОРМАЦИЯ ОБ АВТОРАХ}

Грищенко Леонид Леонидович, доктор юридических наук профессор, профессор кафедры управления органами внутренних дел в особых условиях Академии управления МВД России, Москва, Россия

Таболин Владимир Викторович, доктор юридических наук, профессор, профессор кафедры публичного права и правового обеспечения управления Государственного университета управления, Москва, Россия

Корбельникова Юлия Леонидовна, кандидат юридических наук, доцент, заместитель начальника кафедры государственноправовых дисциплин Академии управления МВД России, Москва, Россия

\section{INFORMATION ABOUT THE AUTHORS}

Grischenko L. Leonidovich, doctor of law, Professor, Professor of Department of management bodies of internal Affairs in the special conditions the Academy of management of MVD of Russia, Moscow, Russia

Tabolin V. Viktorovich, doctor of law, Professor, Professor of the Department of public law and legal support of management, State University of management, Moscow, Russia

Yulia L. Korbelnikova, candidate of law, associate Professor, Deputy head of the Department of state and legal disciplines of the Academy of management of the Ministry of internal Affairs of Russia, Moscow, Russia 